\title{
Synthetic and natural Reference materials for EPMA, LA-ICPMS, LA-MC-ICPMS, SIMS, and Spectroscopic Microanalysis
}

\author{
John M. Hanchar ${ }^{1}$ \\ ${ }^{1 .}$ Department of Earth Sciences, Memorial University of Newfoundland, St. John's, NL A1B 3X5 \\ Canada
}

We have developed a set of synthetic minerals and glasses, and obtained well characterized natural minerals, for use as primary and secondary reference materials for the electron probe microanalyzer (EPMA), laser ablation-inductively coupled plasma mass spectrometry (LA-ICPMS), laser ablationinductively multi-collector coupled plasma mass spectrometry (LA-MC-ICPMS), secondary ion mass spectrometry (SIMS), and spectroscopic microanalysis (e.g., Raman Spectroscopy, Fourier Transform Infrared Spectroscopy), that are available to the earth sciences and materials communities.

All of the synthetic and natural materials have been characterized by powder X-ray diffraction, and Scanning electron microscope (SEM) - energy dispersive spectroscopy (EDS), and many have been further characterized by EPMA, LA-ICPMS, Raman spectroscopy, or Mössbauer spectroscopy and used in house as primary or secondary reference materials for EPMA, LA-ICPMS, or LA-MC-ICPMS microanalysis.

The synthetic materials, for example, include oxides (e.g., $\mathrm{ZrO}_{2}, \mathrm{HfO}_{2}, \mathrm{UO}_{2}, \mathrm{ThO}_{2} \mathrm{Cr}_{2} \mathrm{O}_{3}$ ), silicates (e.g., $\mathrm{ZrSiO}_{4}$ (Fig. 1), $\mathrm{HfSiO}_{4}$ (Fig. 2) $\mathrm{ThSiO}_{4}$ (thorite), ThSiO 4 (huttonite), $\mathrm{Mn}_{2} \mathrm{SiO}_{4}, \mathrm{Mg}_{2} \mathrm{SiO}_{4}, \mathrm{Ni}_{2} \mathrm{SiO}_{4}$, $\mathrm{Zn}_{2} \mathrm{SiO}_{4}, \mathrm{Fe}_{2} \mathrm{SiO}_{5}$ ), orthophosphates (e.g., Pb-free monoclinic $\mathrm{LaPO}_{4}, \mathrm{CePO}_{4}$, and tetragonal $\mathrm{TbPO}_{4}$ DyPO $_{4} \mathrm{YPO}_{4}$ (Fig. 3)) and $\mathrm{Ca}_{5}\left(\mathrm{PO}_{4}\right)_{3} \mathrm{~F}, \mathrm{Ca}_{5}\left(\mathrm{PO}_{4}\right)_{3} \mathrm{Cl}$, and $\mathrm{Ca}_{5}\left(\mathrm{PO}_{4}\right)_{3}(\mathrm{~F}, \mathrm{Cl})$. We have also synthesized three glasses of haplo-andesite composition (e.g., $\mathrm{Si}, \mathrm{Al}, \mathrm{Ca}, \mathrm{Mg}$, and $\mathrm{Na}$ ) undoped, and doped with $\mathrm{Hf}$, Ta, La, Nd, Sm, Gd, Dy, Er, Yb, and Lu, at the 200 ppm and 1000 ppm concentration levels.

The majority of the synthetic materials were grown using a modification of the method described in Hanchar et al. [1] that uses a Li-Mo flux in a vertical tube furnace. Some, however (e.g., $\mathrm{Mn}_{2} \mathrm{SiO}_{4}$, $\mathrm{Mg}_{2} \mathrm{SiO}_{4}, \mathrm{Ni}_{2} \mathrm{SiO}_{4}, \mathrm{Zn}_{2} \mathrm{SiO}_{4}$ ) were grown by fusing oxides at high temperature (e.g., 1400-1600 ${ }^{\circ}$ ) in a glass-making furnace and slowly cooling over a month, or longer, in order to allow the crystals to grow to a useful size (i.e., at least 2-300 micrometers or larger - a few $\mathrm{mm}$ ). The synthetic glasses were made using a modification of the method discussed in Mikova et al [2] in which the oxide and carbonate starting materials, after thoroughly mixing, are fused for four hours, quenched, and ground, and repeated four more times to make a glass that is $>95 \%$ homogeneous at the EPMA, LA-ICPMS, and especially, the ID-MC-ICPMS scale.

The highest purity reagents available (e.g., 99.995\%) were used, when possible for the syntheses. In some cases, however, there were unexpected impurity elements in the starting materials (e.g., $\mathrm{Ti}$ in $\mathrm{SiO}_{2}$; $\mathrm{Hf}$ in $\mathrm{ZrSiO}_{4}$ ) when they were assayed.

The natural minerals that are available include high quality, well characterized, magnetite (Kiruna, Sweden), fluorapatite (several localities including Bear lake, Ontario; Durango, Mexico; Panesqueria, Portugal; Kola, Kovdor, Russia; Sludyanka, Russia) monazite (Parry Sound, Ontario, Trebilcock, Maine), and titanite (Bear lane, Ontario). 
References:

[1] JM Hanchar, RJ Finch, PWO Hoskin, EB Watson, DJ Cherniak and AN Mariano, American Mineralogist, 86 (2001), p 667-680.

[2] J Mikova J Košler, HP Longerich, M Wiedenbeck and JM Hanchar, Journal of Analytical Atomic Spectrometry, 24 (2009) 1244-1252, doi: 10.1039/b900276f.

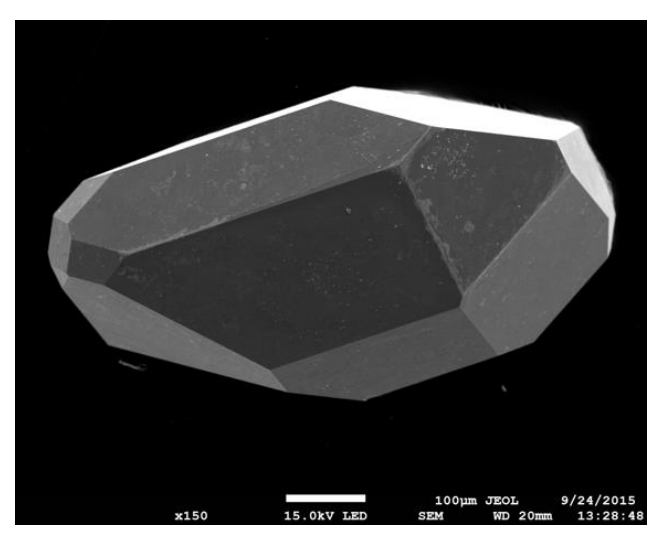

Figure 1. SEM secondary electron image of synthetic zircon crystal.

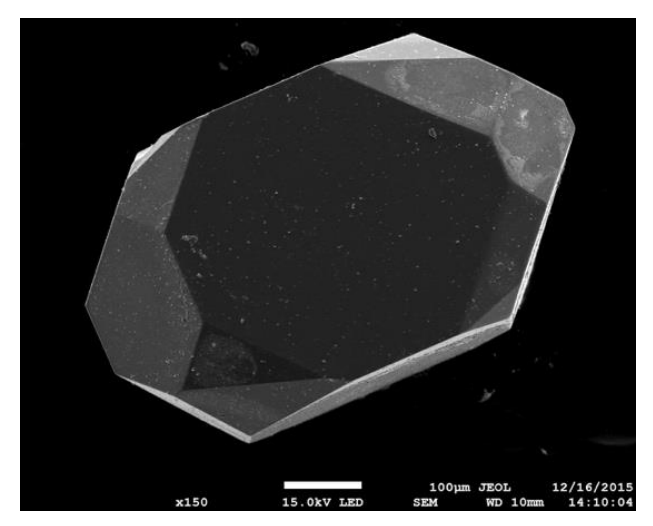

Figure 2. SEM secondary electron image of synthetic hafnon crystal.

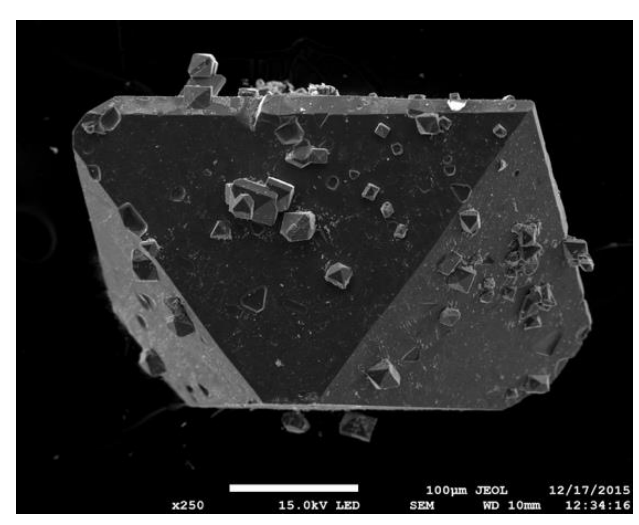

Figure 3. SEM secondary electron image of synthetic $\mathrm{YPO}_{4}$ crystal. 